\title{
Photosynthesis and growth of spring barley: some effects of drought
}

\author{
BY J. E. LEACH \\ Physics Department, Rothamsted Experimental Station, Harpenden, Herts., AL5 $2 J Q$
}

(Received 22 November 1979)

\begin{abstract}
SUMMARY
During the dry summer of 1976 , measurements were made of the photosynthesis, transpiration, respiration, and growth of irrigated (I) and non-irrigated (NI) spring barley growing in large field plots. Using a field enclosure, the photosynthesis of the irrigated barley was measured on 19 separate days during the latter two-thirds of the growing season when the plants were large enough to have measurable gas exchanges. The response of photosynthesis to water stress was determined from 3 days' comparative measurements on the I and NI crops, using both the field enclosure and, on 2 days only, a single-leaf photosynthesis chamber.

Water stress in the NI crop caused large decreases in yield: the dry-matter yields of grain and straw were respectively reduced by 19 and $27 \%$; number of grains (but not grain mass) was also reduced. Field enclosure measurements, which were in good agreement both with values for canopy net photosynthesis derived from the leaf chamber measurements and with estimates of dry-matter production derived from plant weighings, indicated that the net $\mathrm{CO}_{2}$ uptake per unit leaf area was little affected by water stress. Results from the plant weighings and mensurations showed that, during the growing season, the main effect of water stress, mediated by the survival of fewer tillers and the premature senescence of leaves, was a reduction of leaf area (by $40 \%$ ).
\end{abstract}

\section{INTRODUCTION}

In agricultural research there is a continuing need to understand the effects of environmental variables on crop photosynthesis, growth and development. Such understanding is often expressed in mathematical models of crop growth and yield, and these models require field results against which to test their predictions. A variable whose effects have been much studied is water stress and this paper describes measurements at Rothamsted of the effects of large soil moisture deficits on the growth and net photosynthetic rates of field-grown barley.

In the summer of 1976 , when the measurements here reported were made, little rain fell in southern England, and, with the aid of irrigation, opportunity was taken to study the effects of water stress on field crops growing in large plots. The use of large plots is desirable because, in small plots, the measurements can be prone to error because of plot edge effects. However, in years of normal rainfall in England it is not possible to control water supply in field plots unless rain is diverted by shelters or gutters, each of which, in addition to restricting plot size, may also alter the environment. But field studies of water stress, whether on large or small plots, have the advantage in comparison with indoor pot experiments (in which the water supply can readily be controlled) that the patterns of rooting and stress development do represent field behaviour, whereas those in pots may not. The exceptional weather of 1976 thus provided a rare opportunity to study in large plots, and without gutters or shelters, the effects of water stress on a field-growing crop.

The measurements were made using a field enclosure system (Leach, 1979a) and formed a small part of experiments that were primarily designed to study the effects of air temperature and humidity on the photosynthesis of field. grown crops. The results of the temperature and humidity experiments have been reported elsewhere (Leach, 1979b); this present paper, in addition to describing the response of photosynthesis to water stress, also gives results of measurements throughout the growing season of the growth and net photosynthesis of irrigated barley and 
compares the field enclosure measurements of photosynthesis with estimates obtained using a leaf photosynthesis chamber.

The experiments were carried out on two large plots of barley, and reference will be made to measurements made at a neighbouring site, during the same season, on small plots of field-grown barley subjected to various water stresses that were imposed with the aid of automatic rain shelters (Day et al. 1978; Legg et al. 1979). In these rain-sheltered experiments grain and straw yields were substantially reduced by water stress and the yield reductions could be ascribed mainly to changes in leaf area: photosynthesis of individual leaves did not respond to water stress, and although stomatal resistances did respond, they did so for only a few hours in any day, and over the whole season these responses caused little change in yields. The enclosure experiments here reported likewise sought to determine whether water stress mainly affected barley yields by restricting leaf expansion, or whether it affected, in addition, the $\mathrm{CO}_{2}$ assimilation per unit leaf area.

\section{MATERIALS AND METHODS}

Experiment site, crop, agricultural treatments and weather

The field enclosure measurements were made at Great Field I, Rothamsted Experimental Station, on the two plots, each of about 1.0 ha, of an intensive micrometeorological experiment. The soil, a well drained silty clay loam with flints, received $310 \mathrm{~kg} / \mathrm{ha}$ of basal fertilizer $\left(20 \% \mathrm{P}_{2} \mathrm{O}_{5}\right.$ : $20 \% \mathrm{~K}_{2} \mathrm{O}$ ) and $50 \mathrm{~kg} / \mathrm{ha}$ of nitrogen prior to the sowing of Julia barley on 3 March 1976 at a seed rate of $160 \mathrm{~kg} / \mathrm{he}$ in rows $17 \mathrm{~cm}$ apart. One plot, the non-irrigated (NI), received rainfall only; the other, irrigated (I) plot, was watered by oscillating spraylines so as to maintain below $60 \mathrm{~mm}$ its soil moisture deficit. The irrigation requirements were calculated weekly, by Penman's (1970) method, from meteorological data collected at an immediately adjacent site, and irrigations were applied on 22, 28 May, 7, 16 and 24 June. Soil water contents, measured at four sites per plot using a neutron scattering meter (Long \& French, 1967), were used to calculate actual soil moisture deficits (Table 1). After sowing, standard agricultural treatments were given as necessary, but after emergence these were kept to a minimum so that the leaf canopy suffered the least possible damage; and similarly, to avoid canopy distortion through crop lodging, irrigation was discontinued after 24 June.

Most of the enclosure measurements were made during June and July, and the monthly summaries of weather for those 2 months (Rothamsted, 1977) indicate that their mean daily maximum temperatures, at 23.7 and $25.1{ }^{\circ} \mathrm{C}$, were respectively 4.8 and $4.5 \mathrm{~K}$ higher than their long-term means. Monthly sunshine totals for June and July, at 269

Table 1. Actual soil water deficits, derived from neutron scattering measurements, and leaf water potentials, for irrigated $(I)$ and non-irrigated $(N I)$ plots of spring barley at Rothamsted in 1976

\begin{tabular}{|c|c|c|c|c|c|}
\hline \multirow[b]{2}{*}{ Date } & \multirow{2}{*}{$\begin{array}{l}\text { Irrigation } \\
\text { (mm) }\end{array}$} & \multicolumn{2}{|c|}{ Actual soil water deficit (mm) } & \multicolumn{2}{|c|}{ Leaf water potential (MPa) } \\
\hline & & I & NI & I & NI \\
\hline 24 Apr. & - & \multicolumn{2}{|c|}{$24 \pm 2$} & - & - \\
\hline 13 May & - & \multicolumn{2}{|c|}{$55 \pm 3$} & - & - \\
\hline 20 May & - & \multicolumn{2}{|c|}{$81 \pm 4$} & - & - \\
\hline 22 May & 30 & & & - & - \\
\hline 27 May & - & $57 \pm 2$ & $86 \pm 6$ & - & - \\
\hline 28 May & 25 & - & - & - & - \\
\hline 3 June & - & $39 \pm 9$ & $88 \pm 8$ & - & - \\
\hline 7 June & 25 & 二 & 二 & - & - \\
\hline 11 June & - & $57 \pm 13$ & $120 \pm 10$ & - & - \\
\hline 12 June & - & - & 一 & $\left\{\begin{array}{l}-1.47 \pm 0.02^{*} \\
-1.54 \pm 0.02 \ddagger\end{array}\right.$ & $\begin{array}{l}-1.58 \pm 0.03^{*} \\
-1.67 \pm 0.02 \ddagger\end{array}$ \\
\hline 16 June & 30 & - & - & - & - \\
\hline 19 June & - & - & - & $-1.53 \pm 0.02 \dagger$ & $-1.67 \pm 0.03 \dagger$ \\
\hline 23 June & - & $57 \pm 13$ & $141 \pm 17$ & - & - \\
\hline 24 June & 20 & - & - & - & - \\
\hline 26 June & - & 一 & - & $-1 \cdot 67 \pm 0.03 \ddagger$ & $-1.95 \pm 0.06 \ddagger$ \\
\hline 2 July & - & $106 \pm 20$ & $138 \pm 21$ & - & - \\
\hline 9 July & - & $136 \pm 22$ & $179 \pm 20$ & - & - \\
\hline 20 July & - & $112 \pm 23$ & $162 \pm 19$ & - & - \\
\hline 4 Aug. & - & $118 \pm 20$ & $155 \pm 20$ & - & - \\
\hline
\end{tabular}




\section{Photosynthesis and growth of spring barley}

and $245 \mathrm{~h}$, exceeded their long-term means by 66 and $54 \mathrm{~h}$, and the rainfall totals of 7 and $42 \mathrm{~mm}$ were respectively 39 and $12 \mathrm{~mm}$ below average. During this summer, the soil moisture deficit (Table 1) of the NI plot increased throughout most of the growing season, attaining a value of about $140 \mathrm{~mm}$ by the end of June, when it exceeded the I plot deficit by more than $80 \mathrm{~mm}$, affording opportunities for useful measures of plant response to water stress. After $24 \mathrm{June}$, when neither plot was irrigated, the difference between I and NI deficits was generally less than $40 \mathrm{~mm}$. On 12, 19 and 26 June, during the period when soil moisture deficits most differed between I and NI plots, leaf water potentials were measured for both $I$ and NI plents. On these days, leaf water potentials were determined with a pressure bomb for four or more leaves per plot that were removed during late morning or during the afternoon peak of evaporative demand. Their values (Table 1) show that leaf water potentials were lower, i.e. more negative, for the NI plants, being lower by $0.28 \mathrm{MPa}$ ( $2 \cdot 8$ bar) on 26 June; potentials were similar on the neighbouring rain-sheltered experiment (W. Day, personal communication).

\section{Growth and harvest yield measurements}

At 14-day intervals, four $50 \mathrm{~cm}$ lengths of crop row were removed from each plot for growth measurement. These sample lengths, spaced at least $2.0 \mathrm{~m}$ from each other and from any lengths previously sampled, were otherwise located at random within the plots.

The plants were cut at the base of the stem, below ground level, to sever the roots. The sample's total fresh weight and its numbers of main stems and tillers were determined, and on a subsample, comprising about one quarter of the total sample, measurements were made of leaf and stem areas. For each subsample, stems and tillers were measured separately when they could be distinguished (in the first half of the growing season). Leaves were removed and the ear, if it had emerged from its sheath, was separated from the stem. Leaf areas were measured using an electronic planimeter (Paton Industries, Australia), and ear and stem areas were respectively calculated from graduated rule measurements of their length and width and their length and diameter at half height. Each complete subsample, after drying at $80^{\circ} \mathrm{C}$ in a forced-draught oven, was reweighed, and its dry mass and total area of each foliage component were calculated from the ratios dry:fresh weight and subsample fresh weight:total sample fresh weight. No measurements were made of root mass or length.

Yields of grain and straw were derived from harvest samples cut by combined harvester. The samples, two per plot and each $70 \mathrm{~m}$ by $3.0 \mathrm{~m}$, were cut in strips across the plant rows so as to reduce errors arising from uneven sowing.

\section{Photosynthesis measurements}

Using a semi-closed field enclosure system (Leach, 1979a), measurements were made, under conditions of controlled air temperature and humidity and at fixed carbon dioxide concentrations, of the rates of photosynthesis and transpiration of the enclosed barley plants, which occupied $1.5 \mathrm{~m}^{2}$ of ground area. At night, or when the enclosure was covered by black polythene, the plants' dark respiration was measured; and soil and soil plus root respirations were measured with the enclosure respectively overlying bare soil and soil from which the aerial plant parts had been removed immediately prior to measurement.

Measurements of photosynthesis were made throughout the period late May to mid July 1976, but were restricted to those days that were almost cloudless, as on such days the environment within the enclosure could be very closely controlled. For the irrigated (I) barley, measurements were made on 27 and 28 May, on 15 days in June and on 1 and $13 \mathrm{July}$, on the same plants on each occasion. Measurements on an area of non-irrigated (NI) barley were made on 4 and 25 June and 3 July: 3 days only were allocated to the NI plants because too frequent movement of the heavy enclosure would involve great risk of plant damage and because the experiment's main objective was to study the effects of temperature and humidity on the photosynthesis of well-watered crops (Leach, 1979b). On each of these 22 measurement days, photosynthesis was measured throughout the period of net uptake of $\mathrm{CO}_{2}$, usually from just after sunrise to just before sunset, and air temperature was maintained at $18^{\circ} \mathrm{C}$, the vapour pressure deficit between the leaves and enclosure air at about $0.8 \mathrm{kPa}(8 \mathrm{mb})$, and the carbon dioxide concentration at about $320 \mu \mathrm{l} / \mathrm{l}$.

On two of the measurement days, 26 June for I and 3 July for NI plants, the photosynthesis of individual leaves and ears was measured within the enclosure using a portable leaf chamber (Parkinson, 1978). Measurements were made on five ears, and on five leaves in each of the two leaf layers then present. Corresponding estimates for whole canopy photosynthesis were derived from the enclosure gas exchange.

\section{DATA, ANALYSIS AND INTERPRETATION}

Field enclosure measurements of dry-matter production

The 22 days of field enclosure operation each afforded estimates of the daily progressions of 

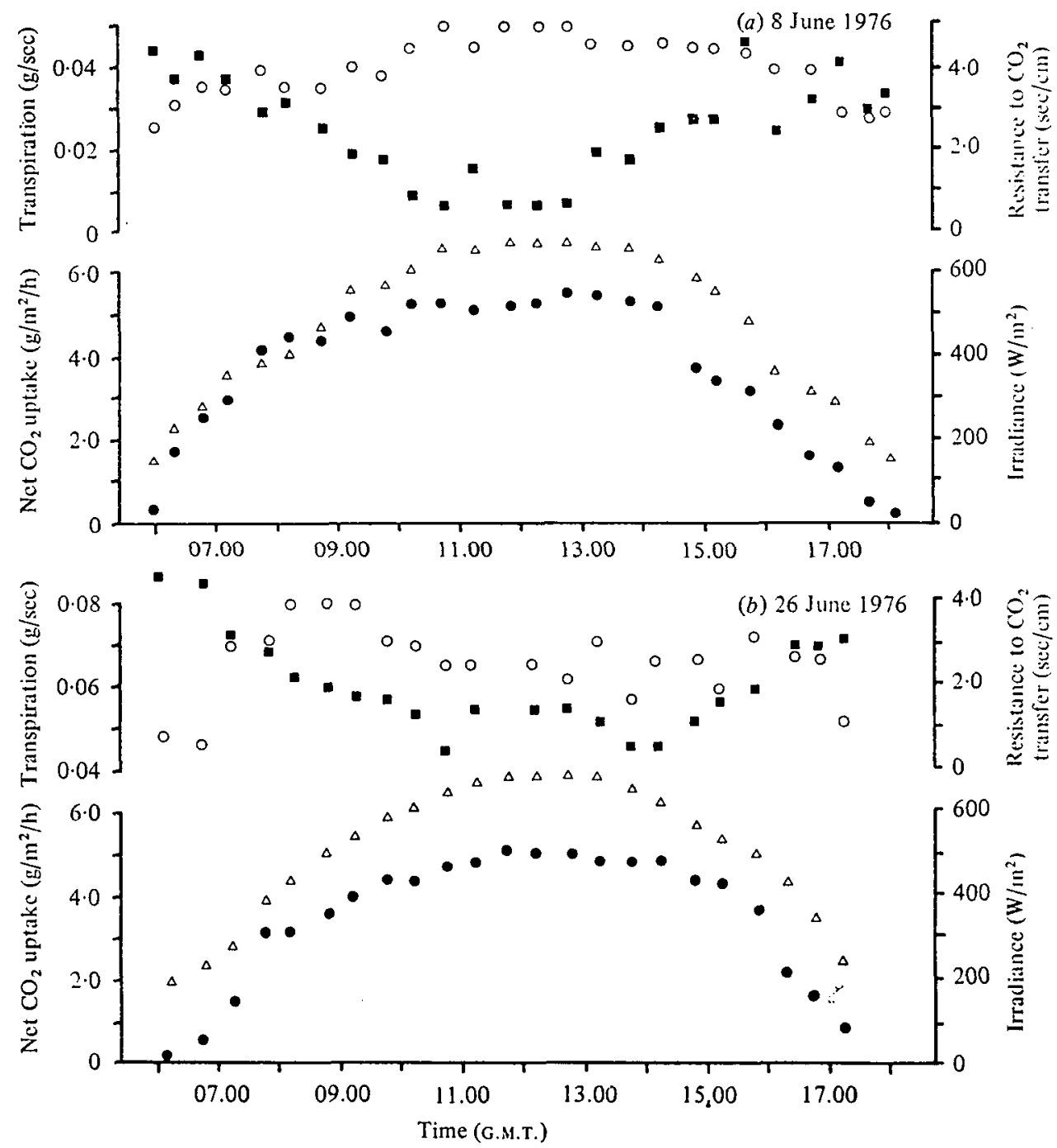

Fig. 1. Diurnal progressions on selected days of irradiance $(\Delta)$, transpiration $(O)$ and net $\mathrm{CO}_{2}$ uptake (O) per unit ground area, and of canopy gas phase resistance (D) to $\mathrm{CO}_{2}$ transfer, for irrigated barley at Rothamsted in 1976. (Measurements made in a field enclosure at $18{ }^{\circ} \mathrm{C}$ and $0.8 \mathrm{kPa}(8 \mathrm{mb}$ ) water vapour pressure deficit.)

solar irradiance, canopy net photosynthesis and canopy transpiration rates. From the latter were derived (as described by Leach, 1979a) values for the canopy gas phase resistances to the transfers of water vapour and carbon dioxide. Figure 1 shows data for two typical days for the I crop: on both days the irradiance varied almost sinusoidally, with a maximum between 12.00 and $13.00 \mathrm{~h}$ G.M.T., and the net uptake of $\mathrm{CO}_{2}$ varied similarly. The irradiance within the enclosure, which was less than that outside because some radiation was reflected and absorbed by the enclosure materials, was usually not sufficiently high that photosynthesis was light saturated for the whole canopy. On all days the canopy gas phase resistance to $\mathrm{CO}_{2}$ transfer, comprising the sum of stomatal and boundary layer resistances to $\mathrm{CO}_{2}$ transfer, and referred to unit ground area, was largest in the morning and evening and least during midday hours; correspondingly, the transpiration rates from which these resistances were derived tended to be higher during the hours of greater irradiance. Results from the measurement of the NI crop (Fig. 2) show a relation between 


\section{Photosynthesis and growth of spring barley}

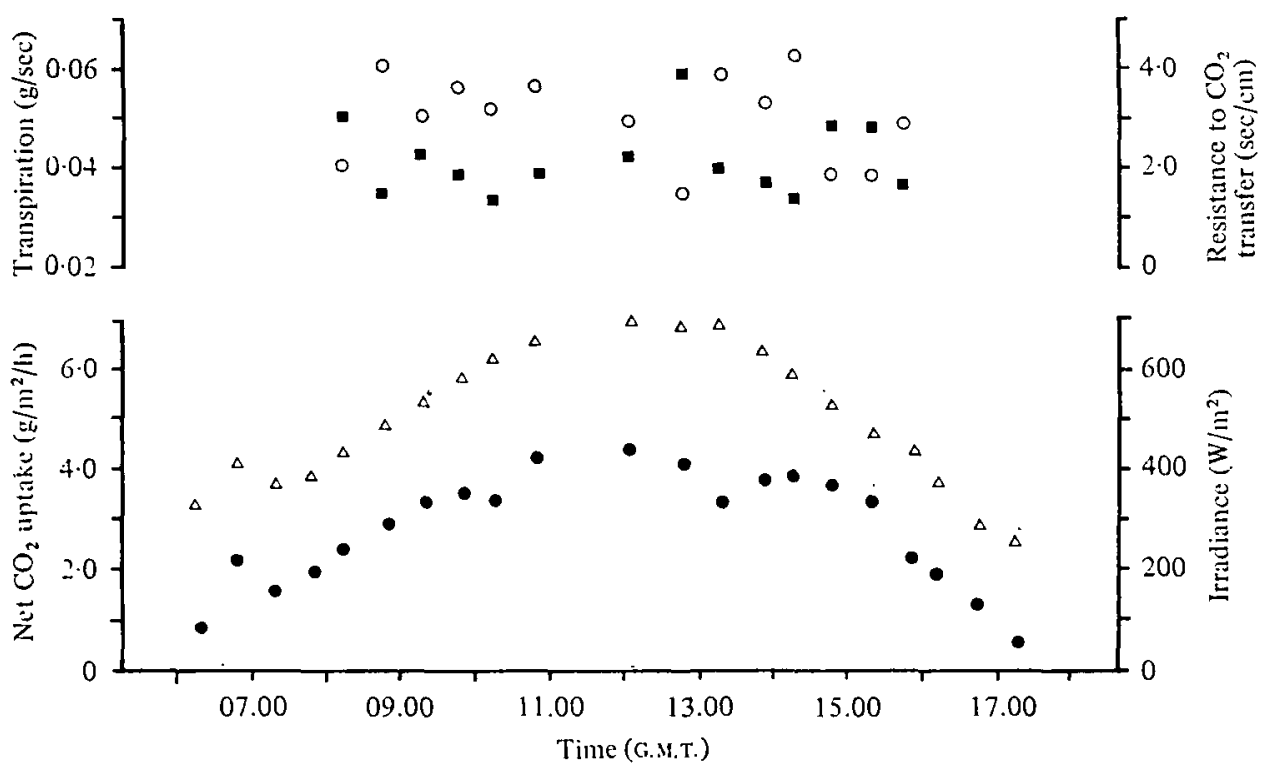

Fig. 2. Diurnal progressions on 25 June 1976 of irradiance $(\Delta)$, transpiration $(O)$ and net $\mathrm{CO}_{2}$ uptake (O) per unit ground area, and of canopy gas phase resistance ( $\square$ ) to $\mathrm{CO}_{2}$ transfer, for non-irrigated barley at Rothamsted. (Measurements made in a field enclosure at $18{ }^{\circ} \mathrm{C}$ and $0.8 \mathrm{kPa}(8 \mathrm{mb}$ ) water vapour pressure deficit.)

$\mathrm{CO}_{3}$ uptake and irradiance that is similar to that for the I crop, but the midday resistances and transpiration rates were so variable within a day and between days that it was not possible to determine whether their values differed significantly from those of the $I$ crop. The maximum rate of net photosynthesis that was observed for the NI crop was $4 \cdot 2 \mathrm{~g} / \mathrm{h} / \mathrm{m}^{2}$ ground area, on $25 \mathrm{Jun} \theta$ when the leaf area index was 1.5 ; the corresponding value for the I crop was $5.4 \mathrm{~g} / \mathrm{h} / \mathrm{m}^{2}$ ground area on 8 June with a leaf area index of $2 \cdot 1$.

From these field enclosure measurements, light response curves were prepared, showing, for each measurement date, the dependence of net $\mathrm{CO}_{2}$ uptake on the solar irradiance, and, by inference, indicating also the change in that dependence as the season progressed. Selections of these curves, respectively for I and NI crops, are displayed in Figs 3 and 4, where measurements taken under increasing and under decreasing irradiance are represented by different symbols, but the curves, fitted by eye, are the averages for both types of data. (If, for each measurement day's curve, the photosynthetic rate be derived that corresponds to an irradiance of $600 \mathrm{~W} / \mathrm{m}^{2}$, then the seasonal course of these particular rates, matching that of leaf area, is of an initial increase to a mid-season plateau and thereafter a decrease as the crop matures and the leaves senesce.) Twenty-two response curves were constructed, and to each of them was fitted Monteith's (1965) model of light distribution and photosynthesis, generating for each measurement day a pair of single leaf photo. synthesis parameters appropriate to that day and its leaf area index (LAI). By interpolating, between measurement days, the LAI values and the leaf parameters, it was thus possible to use Monteith's model to calculate a relationship between gross photosynthesis and irradiance for each of those days on which no enclosure measurements were made. Hence, using the measured and interpolated uptake-irradiance relationships, together with continuous irradiance data that were recorded at the adjacent meteorological station, estimates were derived for the total net uptake of $\mathrm{CO}_{2}$ during each day of crop growth.

However, in using Monteith's model in these interpolations and calculations it was necessary to translate the enclosure measures of net photosynthesis to the estimates of 'gross' photosynthesis that are constituent to the model. This translation was effected through the frequently-used procedure of adding to the net photosynthesis an estimate for respiration measured in the dark. Conversely, the Monteith model predictions of 'gross' photosynthesis were converted into rates of net photosynthesis by subtracting a dark respiration value. It is realized that dark respiration does not 

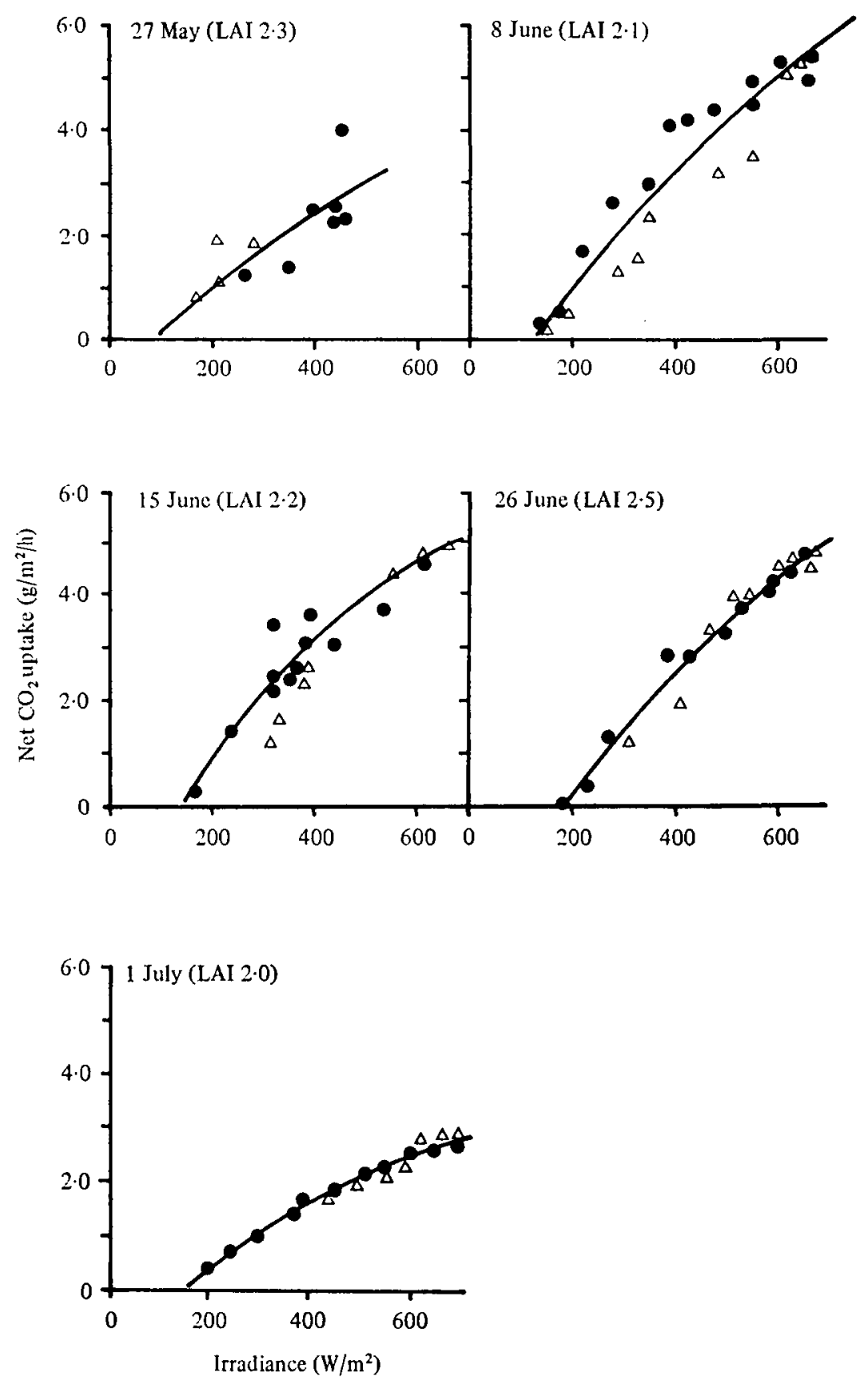

Fig. 3. Dependence on irradiance of net $\mathrm{CO}_{2}$ uptake per unit ground area for irrigated barley during morning $(O)$ and afternoon $(\Delta)$ periods on selected days at Rothamsted in 1976. (Measurements made in a field enclosure at $18^{\circ} \mathrm{C}$ and $0.8 \mathrm{kPa}(8 \mathrm{mb})$ water vapour pressure deficit.) LAI, leaf area index. 
accurately represent respiration occurring during daylight, but within their limitations the foregoing procedures none the less allow useful comparisons of measured and predicted rates of photosynthesis.

The measured values for dark respiration (Table 2) show large but non-systematic variation during the measurement period, 28 May-29 June.
The daytime measures of soil respiration (Table 3) show much less variation, and the irrigated (I) soil respired about one-and-a-half times faster than the non-irrigated (NI). The soil plus root respiration rates, also in Table 3 , showed, for the $I$ plot, an increase from about $0.45 \mathrm{~g} / \mathrm{m}^{2} / \mathrm{h}$ at the beginning of June, to about $0.7 \mathrm{~g} / \mathrm{m}^{2} / \mathrm{h}$, in the third week of
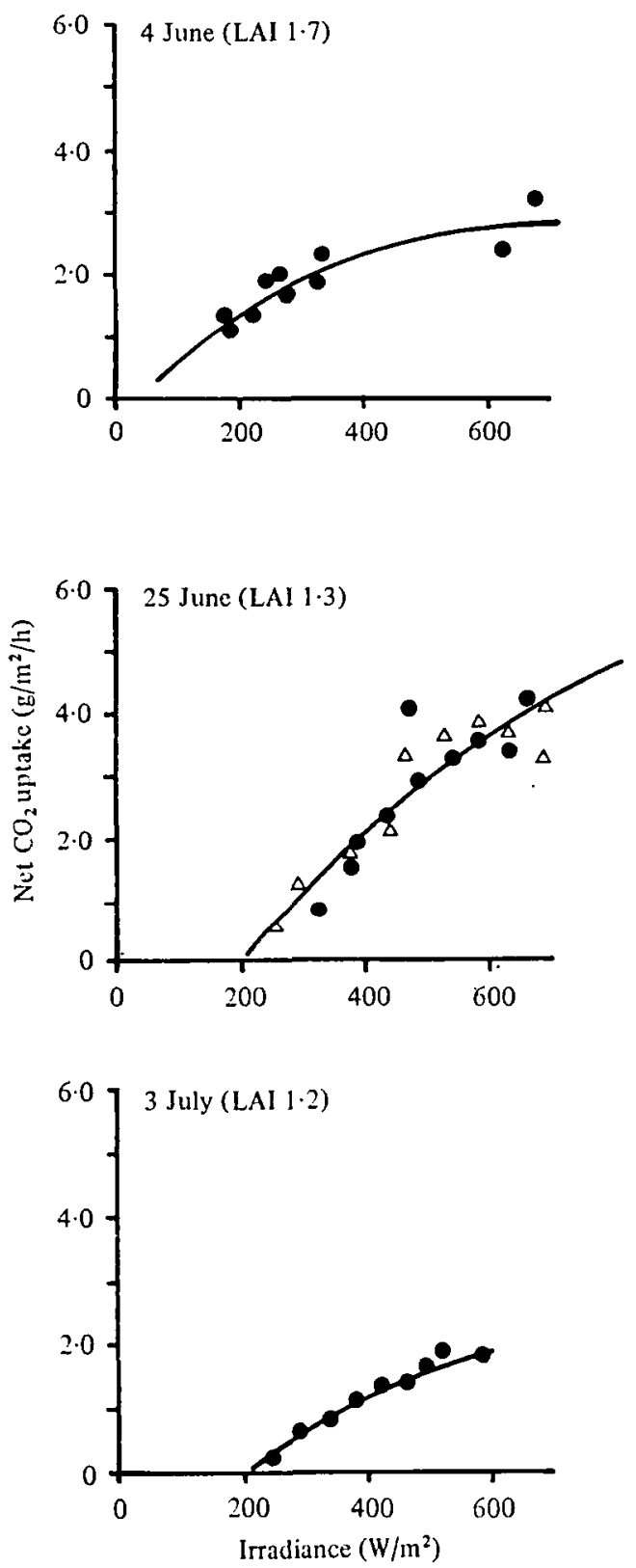

Fig. 4. Dependence on irradiance of net $\mathrm{CO}_{2}$ uptake per unit ground area for non-irrigated barley during morning $(O)$ and afternoon $(\Delta)$ periods on seleoted days at Rothamsted in 1976. (Measurements made in a field enclosure at $18^{\circ} \mathrm{C}$ and $0.8 \mathrm{kPa}(8 \mathrm{mb})$ water vapour pressure deficit.) LAI, leaf area index. 
that month; the rate on the NI plot was, on 7 June, about $80 \%$ of that on the I plot.

Daily totals for the net uptake of $\mathrm{CO}_{2}$ during daylight hours were calculated from the measured irradiances and the measured and interpolated response curves, with allowance being made for additions of $\mathrm{CO}_{2}$ respired by the soil. These totals, less the corresponding estimates of night-time respiration, gave values for the $24 \mathrm{~h}$ net uptake, which, when multiplied by a molecular weight factor of 0.64 that relates carbon and carbohydrate masses, yielded estimates for the daily increments in dry matter. These daily increments were then summed to give values for dry-matter increases during three growing periods, and these are presented in Table 4 as 'uncorrected' field enclosure estimates: uncorrected in that they

Table 2. Dark respiration rates for irrigated $(I)$ and non-irrigated (NI) spring barley, 1976 (measured using a field enclosure apparatus)

\begin{tabular}{|c|c|c|}
\hline \multirow[b]{2}{*}{ Date } & \multicolumn{2}{|c|}{$\begin{array}{l}\text { Dark respiration rate } \\
\left(\mathrm{g} / \mathrm{h} / \mathrm{m}^{2} \text { ground area) }\right.\end{array}$} \\
\hline & I & NI \\
\hline $28 \mathrm{May}$ & $0.37 \pm 0.06$ & - \\
\hline 3 June & $0.40 \pm 0.05$ & - \\
\hline 7 June & $0.82 \pm 0.05$ & - \\
\hline 11 June & $0.58 \pm 0.07$ & - \\
\hline 17 June & $0.48 \pm 0.05$ & - \\
\hline 25 June & $=$ & $0 \cdot 60 \pm 0 \cdot 10$ \\
\hline 26 June & $0.39 \pm 0.06$ & - \\
\hline 29 June & $0.80 \pm 0.08$ & - \\
\hline
\end{tabular}

represent rates of growth in the constant $18^{\circ} \mathrm{C}$ environment of the field enclosure. Their associated uncertainties arise through the imprecisions of measurement of the gas exchanges and from the uncertainties in using daytime measures of dark respiration as estimates for night-time respiration. The 'corrected values' in Table 4 represent estimates for the growth of unenclosed plants that were subject to the natural temperature regime at this Great Field site in 1976. The hourly values of temperature within the crop were known for the whole growing season from the micrometeorological records, and the temperature dependence of the $\mathrm{CO}_{2}$ response of the barley plants was known from other phases of this present study (Table 5) (Leach, 1979b). It was thus possible to determine 'corrected' photosynthetic rates, appropriate to the field temperatures. In the earlier part of the growing season, temperatures were usually between 14 and $25^{\circ} \mathrm{C}$, and the corrected values differed little from the uncorrected, although their uncertainties were slightly greater because of the uncertainties of the adjustment procedure. On and after 23 June, temperatures frequently exceeded $26^{\circ} \mathrm{C}$ for long periods, causing $\mathrm{CO}_{2}$ uptake to be considerably reduced, and this reduction is evidenced in the accompanying 'corrected' values in Table 4. The entries of Table 4 are completed by corresponding but independent estimates, from the weighings of plant samples, for the growth of unenclosed plants; in the light of previous experience, these latter growth increments were assumed uncertain to $\pm 14 \%$. The plant weight measurements and the temperature-corrected field

Table 3. Soil and soil plus root respiration rates for irrigated $(I)$ and non-irrigated $(N I)$ spring barley, 1976 (measured using a field enclosure apparatus)

\begin{tabular}{|c|c|c|c|c|}
\hline \multirow[b]{2}{*}{ Date } & \multicolumn{2}{|c|}{$\begin{array}{l}\text { Soil respiration rate } \\
\text { (g/h/m } / \mathrm{m}^{2} \text { ground area) }\end{array}$} & \multicolumn{2}{|c|}{$\begin{array}{l}\text { Soil plus root respiration rate } \\
\left(\mathrm{g} / \mathrm{h} / \mathrm{m}^{2} \text { ground area) }\right.\end{array}$} \\
\hline & $\mathbf{I}$ & NI & $\mathbf{I}$ & NI \\
\hline 26 May & $0.27 \pm 0.01$ & - & $0.43 \pm 0.06$ & - \\
\hline 7 June & $0.33 \pm 0.01$ & $0.21 \pm 0.06$ & $0.47 \pm 0.06$ & $0.38 \pm 0.04$ \\
\hline 14 June & $0.31 \pm 0.07$ & 一 & $0.71 \pm 0.01$ & 一 \\
\hline 22 June & $0.32 \pm 0.04$ & - & $0.68 \pm 0.08$ & 一 \\
\hline
\end{tabular}

Table 4. Increase in dry mass of irrigated spring barley during three growth periods in 1976: comparison of estimates from plant weighings and from field enclosure and irradiance measurements

Total dry mass increase $\left(\mathrm{kg} / \mathrm{m}^{2}\right.$ ground area)

$\begin{array}{clccc}\text { Growth period } & \text { Growth phase } & \overbrace{\text { Uncorrected }}^{\text {From field enclosure }} & \begin{array}{c}\text { Temperature- } \\ \text { corrected }\end{array} & \begin{array}{c}\text { From plant } \\ \text { weighings }\end{array} \\ \text { 24 May-6 June } & \text { Stem extension } & 0.34 \pm 0.04 & 0.34 \pm 0.06 & 0.26 \pm 0.04 \\ \text { 7 June-20 June } & \text { Flowering and heading } & 0.32 \pm 0.04 & 0.31 \pm 0.06 & 0.28 \pm 0.04 \\ \text { 21 June-5 July } & \text { Grain filling } & 0.41 \pm 0.05 & 0.33 \pm 0.08 & 0.43 \pm 0.06\end{array}$


enclosure measurements of dry-matter increase are seen to agree, within their large uncertainties, for each of the three growth periods.

\section{Growth, photosynthesis and harvest yield}

Results of the observations of plant growth are presented in Table 6. Initially, more plants emerged on the NI plot, but by 24 May sizes and numbers of plants were the same on both plots. Water stress, increasing throughout June on the NI plot (Table 1), is seen to have affected plant mass, shoot number, and green leaf area. Total above-ground plant mass increased throughout the season for $I$ and NI treatments, and it was

Table 5. Temperature correction factors: to adjust field enclosure measurements of photosynthesis made at $18^{\circ} \mathrm{C}$ to values for the photosynthesis of the unenclosed crop at ambient temperatures (spring barley at Rothamsted, 1976)

$\begin{array}{cc}\begin{array}{c}\text { Temperature } \\ \left({ }^{\circ} \mathrm{C}\right)\end{array} & \text { Factor } \\ 15.0 & 0.88 \\ 17.5 & 1.00 \\ 20.0 & 1.09 \\ 22.5 & 1.14 \\ 25.0 & 1.08 \\ 27.5 & 0.90 \\ 30.0 & 0.70\end{array}$

only during July that the weight of the I plants significantly exceeded that of the NI. Number of shoots was influenced by late tillering on both plots, but after 5 July most young tillers died on the NI plot, and numbers of shoots increased on the I plot only. Similar behaviour was observed in the neighbouring rain-sheltered experiment (D. W. Lawlor, personal communication). It was green leaf area that most showed the effect of drought in the experiment here reported: through June and July the NI plot had 30 or $40 \%$ less leaf than did the I plot. (Both plots had less leaf area than might be expected: the maximum leaf area index was $2 \cdot 7$, much lower than the $4 \cdot 5$ observed on the rainsheltered experiment. It is possible that this lack of leaf was due to a shortage of nitrogen that can be plausibly explained in terms of the site's previous cropping.)

The areas of leaf and ear (Table 6) and the measurements by leaf chamber of the rates of net photosynthesis for single leaf and ear allowed calculation of the rate of net photosynthesis, at $550 \mathrm{~W} / \mathrm{m}^{2}$, of the whole crop canopy. Values for single leaf photosynthesis for the 2 days of leaf chamber measurement (Table 7) showed no significant difference between $\mathrm{I}$ and NI plants nor, for the I plants, between ears and leaves. The estimates for whole canopy photosynthesis that were derived from these leaf chamber measurements are also shown in Table 7, and are there

Table 6. Total numbers of shoots, above-ground dry mass and leaf area of irrigated $(I)$ and non-irrigated (NI) spring barley, 1976

\begin{tabular}{|c|c|c|c|c|c|c|}
\hline Date & Plot & $\begin{array}{c}\text { Total } \\
\text { above-ground } \\
\text { dry mass } \\
\left(\mathrm{kg} / \mathrm{m}^{2}\right)\end{array}$ & $\begin{array}{c}\text { Total no. } \\
\text { of shoots } \\
\left(\times 10^{2} / \mathrm{m}^{2}\right)\end{array}$ & $\begin{array}{c}\text { Green } \\
\text { leaf area } \\
\left(\mathrm{m}^{2} / \mathrm{m}^{2}\right)\end{array}$ & $\begin{array}{c}\text { Green } \\
\text { stem area } \\
\left(\mathrm{dm}^{2} / \mathrm{m}^{2}\right)\end{array}$ & $\begin{array}{c}\text { Green } \\
\text { ear area } \\
\left(\mathrm{dm}^{2} / \mathrm{m}^{2}\right)\end{array}$ \\
\hline 13 May & $\begin{array}{l}\text { I } \\
\text { NI }\end{array}$ & $\begin{array}{l}0 \cdot 10 \\
0 \cdot 14\end{array}$ & $\begin{array}{l}6 \cdot 6 \\
8 \cdot 8\end{array}$ & $\begin{array}{l}1 \cdot 6 \\
2 \cdot 2\end{array}$ & $\begin{array}{l}0.17 \\
0.24\end{array}$ & - \\
\hline 24 May & $\begin{array}{l}\text { I } \\
\text { NI }\end{array}$ & $\begin{array}{l}0.32 \\
0 \cdot 33\end{array}$ & $\begin{array}{l}9 \cdot 1 \\
8 \cdot 7\end{array}$ & $\begin{array}{l}2 \cdot 3 \\
2 \cdot 7\end{array}$ & $\begin{array}{l}4 \cdot 1 \\
4 \cdot 3\end{array}$ & - \\
\hline 7 June & $\begin{array}{l}\mathrm{I} \\
\mathrm{NI}\end{array}$ & $\begin{array}{l}0.57 \\
0.55\end{array}$ & $\begin{array}{l}8.9 \\
6.5\end{array}$ & $\begin{array}{l}2 \cdot 1 \\
1 \cdot 5\end{array}$ & $\begin{array}{l}18 \cdot 5 \\
16 \cdot 3\end{array}$ & $\begin{array}{l}0.01 \\
0.10\end{array}$ \\
\hline 21 June & $\begin{array}{l}\text { I } \\
\text { NI }\end{array}$ & $\begin{array}{l}0.85 \\
0.96\end{array}$ & $\begin{array}{l}8 \cdot 2 \\
7 \cdot 8\end{array}$ & $\begin{array}{l}2 \cdot 3 \\
1 \cdot 3\end{array}$ & $\begin{array}{l}22 \cdot 5 \\
21 \cdot 1\end{array}$ & $\begin{array}{l}2 \cdot 8 \\
3 \cdot 1\end{array}$ \\
\hline 5 July & $\begin{array}{l}\text { I } \\
\text { NI }\end{array}$ & $\begin{array}{l}1.28 \\
0.85\end{array}$ & $\begin{array}{l}7 \cdot 8 \\
7 \cdot 3\end{array}$ & $\begin{array}{l}2 \cdot 0 \\
1 \cdot 2\end{array}$ & - & - \\
\hline 19 July & $\begin{array}{l}\text { I } \\
\text { NI }\end{array}$ & $\begin{array}{l}1 \cdot 85 \\
1 \cdot 15\end{array}$ & $\begin{array}{r}11 \cdot 9 \\
7 \cdot 8\end{array}$ & - & - & - \\
\hline $\begin{array}{c}\text { Representative } \\
\text { uncertainties }\end{array}$ & & $\pm 10 \%$ & $\pm 1 \cdot 0$ & \pm 0.2 & $\pm 10 \%$ & $\pm 10 \%$ \\
\hline
\end{tabular}

Calculated from plant measurements on six dates of $4 \times 50 \mathrm{~cm}$ row samples from 1.0 ha plots; all entries relate to unit ground area.

The crops were sown on 3 March, germinated by 25 March, showed visible response to irrigation by 27 May, continued plant extension until 16 June, had ears fully grown by 20 June and were harvested on $27 \mathrm{July}$; the NI crop matured 6 days earlier than the I crop. 
Table 7. Leaf chamber measurements of photosynthetic rates of single leaves and ears of irrigated (I) and non-irrigated (NI) spring barley, 1976

\begin{tabular}{|c|c|c|c|c|c|c|}
\hline \multirow[b]{2}{*}{ Date } & \multirow[b]{2}{*}{ Plot } & \multicolumn{3}{|c|}{$\begin{array}{l}\text { Single ear and leaf measurements of net } \\
\text { photosynthesis per unit ear or leaf area } \\
\qquad\left(\mathrm{g} / \mathrm{m}^{2} / \mathrm{h}\right)\end{array}$} & \multicolumn{2}{|c|}{$\begin{array}{l}\text { Canopy net photosynthesis } \\
\text { per unit ground area* } \\
\qquad\left(\mathrm{g} / \mathrm{m}^{2} / \mathrm{h}\right)\end{array}$} \\
\hline & & Ear & Leaf 9 & Leaf 8 & $\underset{\text { leaf }}{\text { From single }}$ & $\begin{array}{l}\text { From field } \\
\text { enclosure }\end{array}$ \\
\hline $\begin{array}{l}26 \text { June } \\
3 \text { July }\end{array}$ & $\begin{array}{l}\text { I } \\
\text { NI }\end{array}$ & $1 \cdot 62 \pm 0.22$ & $\begin{array}{l}1.73 \pm 0.22 \\
1.49 \pm 0.12\end{array}$ & $\begin{array}{l}1.78 \pm 0.22 \\
1.86 \pm 0.10\end{array}$ & $\begin{array}{l}4.4 \pm 0.6 \\
2 \cdot 2 \pm 0.3\end{array}$ & $\begin{array}{l}4.9 \pm 0.2 \\
1.9 \pm 0.1\end{array}$ \\
\hline
\end{tabular}

\footnotetext{
* Canopy net photosynthetic rates calculated from single leaf measurements and known leaf area and compared with measurements of canopy net photosynthesis measured with a field enclosure. All data relate to an irradiance of $550 \mathrm{~W} / \mathrm{m}^{2}$.

$\uparrow$ Not measured: ears yellow.
}

compared with those obtained at the same time (and the same irradiance) using the field enclosure. The two sets of estimates agree within their uncertainties, of which those for the chamberderived values were due, in part, to a lack of measurement of the distribution of the foliage among the different leaf layers (in accord with visual observation most of the leaf was assumed to reside in leaf layer 8).

The programme of field enclosure measurements sought to determine whether water stress affected the net $\mathrm{CO}_{2}$ assimilation per unit leaf area. To this end, enclosure measurements on I and NI plots were made on pairs of days, with the days within each pair sufficiently close together that their radiation environments, and the plants' ages, were similar. However, because of its smaller leaf area, the NI crop intercepted less light, and had more leaves near to light-saturation, than did the I crop. It was therefore not appropriate to compare on a unit leaf area basis the measured rates of canopy photosynthesis of I and NI plants. Instead, the data were analysed so as to yield information about the effect of water stress on the parameters $a, b$ in the relation (Monteith, 1965):

$$
P_{g}=\left(\frac{a}{S}+b\right)^{-1}
$$

which may be made to relate to a crop or a leaf, and in which $P_{g}$ is the rate of 'gross' photosynthesis and $S$ the irradiance; $a$ is inversely proportional to the efficiency of light conversion, and for small $S, P_{g} \rightarrow S / a ; 1 / b$ is the maximum rate of 'gross' photosynthesis, $P_{\max }$, when light is non-limiting (i.e. at large $\left.S, P_{0} \rightarrow 1 / b\right)$. Under normal field conditions $P_{\max }$ is determined by the rate of $\mathrm{CO}_{2}$ transport to the chloroplasts and is therefore dependent upon the $\mathrm{CO}_{2}$ concentration and the resistance to $\mathrm{CO}_{2}$ transfer. In these experiments the $\mathrm{CO}_{2}$ concentration was maintained constant close to ambient; $b$ is then proportional to the total resistance to $\mathrm{CO}_{2}$ transfer.

From the enclosure measurements, suitably corrected for soil and root and dark respiration, crop parameters $a_{c}$ and $b_{c}$ were derived through equation (1). Parameters $a_{l}$ and $b_{l}$, appropriate to individual leaves, can be uniquely related to the $a_{c}$ and $b_{c}$ through Monteith's (1965) model of photosynthesis provided that all leaves on a particular treatment can be assumed to have the same $a_{l}$ and $b_{l}$.

On this assumption, the $a_{l}$ and $b_{b}$ for I and NI crops were calculated and are displayed in Table 8. In only one comparison, for $b_{l}$ of 25-26 June, is there a significant difference between treatments, and that, in six comparisons, could be fortuitous, although it did occur when the difference in soil moisture deficit between I and NI plots, at $84 \mathrm{~mm}$, was maximal, much exceeding the $59 \mathrm{~mm}$ and $32 \mathrm{~mm}$ that respectively obtained during the comparisons of 4-8 June and 1-3 July. However, direct measurement on single leaves by the leaf chamber (Table 7) showed no difference between the net photosynthetic rates of $I$ and NI plants. For the data of 25-26 June (Table 8), the values for the total resistance to transfer of $\mathrm{CO}_{2}$ that correspond to the listed $b_{l}$ values and to the known $\mathrm{CO}_{2}$ concentration of $320 \mu \mathrm{l} / 1$ were $(2 \cdot 6 \pm 0.8)$ and $(5 \cdot 5 \pm 1.0) \mathrm{sec} / \mathrm{cm}$ for the $I$ and NI leaves respectively. This total resistance is composed of canopy gas phase (stomatal plus aerodynamic) and internal components, and differences in total resistance could therefore be caused by differences in canopy gas phase resistance, in internal resistance, or in both. Figures 1 and 2 show values for the canopy gas phase resistances, and, as was remarked earlier, any difference between I and NI resistances was masked by the variability of the latter. Furthermore, there were no independent measures of stomatal resistance, as by a porometer. 
Table 8. Photosynthetic leaf constants $a_{l}$ and $b_{l}$ for irrigated $(I)$ and non-irrigated $(N I)$ spring barley, 1976

$\begin{array}{rlcc}\text { Date } & \text { Plot } & a_{l}\left(\mathrm{~W} / \mathrm{m}^{8} \operatorname{per} \mathrm{g} / \mathrm{m}^{2} / \mathrm{h}\right) & b_{l}\left(\mathrm{~g} / \mathrm{m}^{2} / \mathrm{h}\right)^{-1} \\ \text { 4 June } & \text { I } & 46 \pm 10 & 0 \cdot 26 \pm 0 \cdot 04 \\ \text { 8 June } & \text { NI } & 48 \pm 14 & 0 \cdot 20 \pm 0 \cdot 05 \\ \text { 26 June } & \text { I } & 58 \pm 8 & 0 \cdot 13 \pm 0 \cdot 04 \\ \text { 25 June } & \text { NI } & 71 \pm 18 & 0 \cdot 28 \pm 0 \cdot 05 \\ \text { 1 July } & \text { I } & 81 \pm 10 & 0 \cdot 17 \pm 0 \cdot 04 \\ \text { 3 July } & \text { NI } & 84 \pm 19 & 0 \cdot 15 \pm 0.08\end{array}$

Table 9. Final dry mass yields* at harvest (27 July) of irrigated (I) and non-irrigated (NI) spring barley, 1976

$\begin{array}{lcc} & \text { I } & \text { NI } \\ \text { Grain yield }(t / h a) & 4 \cdot 3 & 3 \cdot 5 \\ \text { Straw yield }(t / h a) & 3 \cdot 0 & 2 \cdot 2 \\ \text { Mean grain mass }(\mathrm{mg}) & \mathbf{3 1} & \mathbf{3 2} \\ \text { Number of grains } \times 10^{8} / \mathrm{ha} & 139 & 110\end{array}$

All entries may be assumed uncertain to $\pm 5 \%$.

* Yields derived from combined harvesting on 27 July are considerably less than those obtained on 19 July from plant weighings (Table 5). The difference is in part due to the different methods of harvesting, in part to the large respiration losses during the hot weather between 19 and $27 \mathrm{July}$, and in part to the uncertainties of measurement.

It is thus not possible to indicate whether the differences of 25-26 June (if they be real) between $I$ and NI plants, in their values for $b_{l}$ and total resistance, should be ascribed to differences in stomatal or in internal factors. In the rainsheltered experiment, on small plots, significant differences in stomatal resistance did result from the different water stress treatments. Rates of 'true' gross photosynthesis, using ${ }^{14} \mathrm{CO}_{2}$, were also measured in the rain-sheltered experiment; the rates showed little dependence on water stress, except for a possible negative correlation under conditions of high irradiance (D.W. Lawlor, personal communication).

In the large plot experiment here reported, the harvest data (Table 9) show the NI crop to have yielded $19 \%$ less grain and $27 \%$ less straw than did the I crop. There was a similar reduction, of $21 \%$, in the number of grains per unit ground area, although the mean grain mass was the same on both treatments. On similar treatments in the rain-sheltered experiment, which were hand rather than combine harvested, there were similar reductions of 26,28 and $20 \%$ respectively in grain and straw yields and in number of grains. A detailed analysis of the effects of drought, and of time of drought, on yields and yield components for both the large plot and the small plot experiments has been reported by Day et al. (1978).

\section{DISCUSSION AND CONCLUSIONS}

The field enclosure and leaf chamber measurements showed that the net $\mathrm{CO}_{2}$ assimilation per unit leaf area was affected little if at all by water stress. From the neighbouring rain-sheltered experiment Legg et al. (1979) concluded that water stress mainly affected growth by reducing leaf area and by causing premature senescence of leaves, whereby stressed plants intercepted less radiation than did unstressed ones. Similarly, in the large plot experiment here reported, leaf area on the NI plot was, from mid-June onward (Table 6), some $40 \%$ less than on the I plot; less because fewer tillers survived and perhaps because the individual leaves were smaller (D.W. Lawlor, personsl communication, found that leaves were smaller on water-stressed treatments in the rain-sheltered experiment). Correspondingly, at harvest (Table 9) the dry-matter yields of grain and straw were respectively 19 and $27 \%$ less on the NI plot than on the I. Taken together, these findings support the suggestion of Hsiao \& Acevedo (1974) that leaf expansion is more sensitive to water stress than is $\mathrm{CO}_{2}$ assimilation per unit leaf area.

For wheat, Lawlor (1976) has reported that water stresses that are sufficient to decrease leaf water potentials are able also to reduce net photosynthesis and to increase stomatal and mesophyll resistances. However, in the experiment on barley here reported, net photosynthetic rates per unit area of single leaves showed no dependence on water stress ('Table 7, 2 days' measurements on I and NI plants). Furthermore, stomatal resistances, as evidenced by the field enclosure measurements of canopy resistance, showed much scatter but little water stress dependence, except for a possible suggestion (Table 8) of an increase in the leaf parameter $b_{l}$ under conditions of very high soil moisture deficit. Further measurements, of greater precision, will be needed in order to determine the stress dependence, if any, of the photosynthetic rates of field growing crops.

Notwithstanding the imprecision of the canopy resistance measurements, the field enclosure has, in the researches here reported, proved capable of giving valuable and unbiased estimates of photo- 
synthesis for half-hour and longer periods. The data of Table 4 support this contention, showing, within their large uncertainties, that the field enclosure estimates of dry-matter production agree with estimates derived from plant weighings. Furthermore, in a year less climatically extreme than 1976 there would be little need for the large and necessarily uncertain temperature corrections that had to be applied to the Table 4 results. Similarly, Table 7 shows acceptable agreement between the estimates for canopy net photosynthesis that were independently derived from field enclosure and from leaf chamber measurements. A check on the accuracy of the enclosure measurements could also be made by the calculation of a complete carbon balance for a growing crop. However, such a balance involves uncertainty in the measurement of respiration and in allowing for the death of plant material, particularly of roots, and is thus unlikely to give a comparison any more precise than those of Tables 4 and 7 and was therefore not attempted in this present investigation.

In this 1976 experiment on the Great Field soil the effects of water stress were manifest at harvest in the reductions in grain and straw yields and in number of grains (Table 9). Analysis of a long series of experiments on the irrigation of cereals and other crops on this particular soil (French \& Legg, 1979) has tentatively shown that its limiting soil water deficit, i.e. the deficit below which there is no yield response to irrigation, is about $100 \mathrm{~mm}$ for spring barley. In the experiment here reported, the deficit of the NI plot exceeded $100 \mathrm{~mm}$ for much of the season (Table 1), but that of the I plot was maintained below $100 \mathrm{~mm}$ until, to prevent lodging, irrigation was terminated on 24 June; the I plot deficit exceeded $100 \mathrm{~mm}$ throughout most of the grain-filling period (Table 1). Yields on both I and NI plots would therefore have been affected by water stress. From the neighbouring rain-sheltered experiment, which sought to investigate the effects of both the intensity and the timing of drought on the yield and yield components of spring barley, Day et al. (1978) concluded that water stress occurring late in the life of a spring barley crop has the effect of reducing mean grain mass. That conclusion is supported by the finding in the current experiment that grain mass was the same for both I and NI plants (Table 9), which each suffered large water stress from early July onwards.

The limiting soil moisture deficit for a particular soil is known to depend on the available water holding capacity of that soil (French \& Legg, 1979), and that capacity depends in turn on the soil type and depth and on the rooting characteristics of each particular crop. For example, the limiting soil water deficit for spring barley on the light sandy soil at Woburn is $40 \mathrm{~mm}$ (Penman, 1971), much less than the $100 \mathrm{~mm}$ appropriate to the Rothamsted Great Field soil. Furthermore, for any particular soil and crop, the soil's fertility and the incidence of disease are likely to have influences that interact with those of soil moisture deficit in imposing water stress upon the plants. The findings of this present work in relation to the effects of water deficit on rates of soil and root respiration ('Table 3), on rates of photosynthesis (Table 7) and on parameters of photosynthesis models (Table 8), and on crop yields (Table 9) must therefore be interpreted as an indication of spring barley's response to water stress on this specific soil under one particular regime of good farm management.

I should like to thank $\mathrm{Mr}$ B. K. French and Mr J. Croft for irrigation work and for calculating soil moisture deficits, Drs W. Day, B. J. Legg and K.J. Parkinson for helpful discussions, and Dr T. Woodhead for help in preparing this paper.

\section{REFERENCES}

Day, W., LegG, B. J., French, B. K., Johnston, A. E., Lawlor, D. W. \& De C. Jeffers, W. (1978). A drought experiment using mobile shelters: the effect of drought on barley yield, water use and nutrient uptake. Journal of Agricultural Science, Cambridge 91, 599-623.

French, B. K. \& LeGG, B. J. (1979). Rothamsted irrigation 1964-76. Journal of Agricultural Science, Cambridge 92, 15-37.

Hsiao, T. C. \& Acevedo, E. (1974). Plant responses to water defioits, water use efficiency, and drought resistance. Agricultural Meteorology 14, 59-84.

LAWLOR, D. W. (1976). Water stress induced changes in photosynthesis, photorespiration, respiration and $\mathrm{CO}_{2}$ compensation concentration of wheat. Photosynthetica 10, 378-387.
LEACH, J. E. (1979a). A field enclosure apparatus for measuring crop photosynthesis. Annals of Applied Biology 92, 125-132.

LEACH, J. E. (1979b). Some effects of air temperature and humidity on crop and leaf photosynthesis, transpiration and resistance to gas transfer. Annals of Applied Biology 92, 287-297.

Legg, B. J., Day, W., Lawlor, D. W. \& Parkinson, K. J. (1979). The effects of drought on barley growth: models and measurements of the relative importance of leaf area and photosynthesis rate. Journal of Agricultural Science, Cambridge 92, $703-716$.

Long, I. F. \& French, B. K. (1967). Measurement of soil moisture in the field by neutron moderation. Journal of Soil Science 18, 149-166. 
Monteite, J. L. (1965). Light distribution and photosynthesis in field crops. Annals of Botany 29, 17-37.

Parkinson, K. J. (1978). Photosynthesis: field studies. Report, Rothamsted Experimental Station for 1977, Part 1, pp. 201-202.

Penman, H. L. (1970). Woburn irrigation, 1960-68. IV. Design and interpretation. Journal of Agricultural Science, Cambridge 75, 69-73.
Penman, H. L. (1971). Irrigation at Woburn. VII. Report, Rothamsted Experimental Station for 1970 , Part 2, pp. 147-170.

ROTHAMSTED (1977). Weather tables. Report, Rothamsted Experimental Station for 1976, Part 1, p. 346. 